\title{
Congregations, Audiences, Actors: Religious performance and the individual in mid-nineteenth-century Nottingham.
}

Jo Robinson and Lucie Sutherland

\section{Introduction}

On 30 November, 1860, the Nottingham Journal reported to its readers that the 'anomalous practice of conducting public worship in a theatre, commenced in London last winter, has extended to Nottingham':

On Saturday night placards were posted on the walls in the poor, thickly populated areas of the town, announcing that a religious service would be held in the Theatre, St. Mary's Gate, and inviting the attendance of persons who were not in the habit of going to places of worship (30 November 1860, 5).

The 'novelty of such a service at such a place', reported the paper, caused an 'immense and noisy crowd' to attend - 'all parts of the building were crowded, and when the doors were closed numbers were left outside'. The police officers who were present to assist the doorkeepers 'were altogether unable to preserve anything like order', although the sermon itself, it was noted, secured 'marked attention, unbroken by any interruption'.

The reporting of this service, and of the ones that followed it in the theatre and in other secular venues in the town, mixed religious and theatrical discourses to convey the complex reactions provoked by these public performances of religion, which took place in unexpected public spaces and in which differing expectations of behaviour and performance came into conflict. Writing of the second such service a week later, for example, the Journal reported that:

The behavior of the 'congregation', was certainly more orderly when they had taken their places, but at times the old spirit of the gallery would make itself 
apparent by the emission of those sounds with which it is so intimately connected (7 December 1860, 5).

Here practices from one public - that of the theatre audience - seemed to bleed through into those of another - the religious congregation - but the anxieties caused by the move from church to theatre soon focused on the nature of the individuals making up those publics, and their appropriate place within the society of the town. By the time of the third service, held on 9 December 1860, the preacher, Captain Orr, issued a warning to particular members of the assembled congregation:

The services at that place were not, he said, intended for them, but for the masses who would not attend religious services elsewhere. He was afraid that to gratify a feeling of curiosity some persons had left their own places of worship to occupy seats there, which, judging by the crowd he saw in the street, would have been filled by others who would not go to the churches and chapels they had left (14 December 1860, 5).

Taking our cue from such reports of congregations occupying different kinds of public spaces, and the articulation of anxiety over which 'public' was the invited audience for these services, this chapter addresses the place, practice and performance of audiences for formal religious events in Nottingham in the mid-nineteenth-century. Analyzing the range of faithrelated activities and competing secular events available to residents of the town, we demonstrate how, by mapping choice, attendance and practice, the role of the individual subject within the public spheres of religion and wider society may be more fully understood.

The concept of mapping is integral to this work. Charting the geography of religion within societies, Lily Kong recognizes that 
socially constructed religious places overlap, complement or conflict with secular places and other socially constructed religious places in the allocation of use and meaning. [...] Even while the sacred is often constructed, and gathers meaning in opposition to the secular, place is often multivalent, and requires an acknowledgement of simultaneous, fluctuating and conflicting investment of sacred and secular meanings in any one site (212).

Kong's notion of the overlap, complement or conflict between sacred and secular spaces is key both to the approach of this chapter and to the wider research project which underpins it: the 'Mapping Performance Culture: Nottingham 1857-1867' project, funded by the UK Arts and Humanities Research Council and led by Jo Robinson and Gary Priestnall at the University of Nottingham. This interdisciplinary collaboration between theatre history and geography has sought to investigate the performance culture of one provincial town via the creation of a web-based, interactive map that draws on an extensive database of performance events within the eleven years covered by the project (www.nottingham.ac.uk/mapmoment). The map, which operates primarily in terms of space but also in terms of time, with the ability to 'play' events across the years 1857-67, prompts exploration of Kong's 'multivalent', 'simultaneous, fluctuating and conflicting' usage and meanings of sites, as it situates the various sites of performance - whether key venues such as established churches and concert halls, or more ephemeral performance spaces such as circuses and portable theatres - within the town in relation to one another and to their patterns of public usage for different kinds of performance events. ${ }^{1}$

\footnotetext{
${ }^{1}$ For further information on the AHRC, please see www.ahrc.ac.uk. We also acknowledge the help of our project partners, Nottingham City Libraries; Nottinghamshire County Archives, and the Manuscripts and Special Collections team at Nottingham University. See Robinson et al (2011) for a fuller description of the project.
} 
This stressing of connections and relationships between different performance events and between the members of the audiences or congregations who may have attended them is key to our argument here, for as Michael Booth reminds us, the Victorian audience 'lived in its own culture and its own network of economic and social relationships; it did not exist only in auditoriums for the benefit of the scholar' (10). This is just as true of congregations: congregation members were, and remain, employers, workers, and potential members of the audience for other events. Thus the individual member of any congregation - whether in established church, dissenting chapel or a member of the public attending a religious service in a secular venue - must be situated within a complex of interrelationships between congregations and other audience communities, and between religious and other cultures within the wider society in which he or she lives. Within such complex interrelationships, this chapter argues that religious performance, within and beyond places of worship, provided an opportunity for individuals in the provincial town of Nottingham to exercise choice and foreground subjective identity in a rapidly expanding and changing urban environment.

\section{The religious landscape of Nottingham}

It is essential to acknowledge that such playing out of subjectivity was made possible, but also circumscribed, by the increasing fragmentation of social interaction and the development of separate leisure time identified by Peter Bailey in his Popular Culture and Performance in the Victorian City. As 'the coherent and readily comprehensible pattern of social life [...] was increasingly exchanged for a pattern of life notable for its discontinuities of experience in terms of time, space and personnel,' Bailey argues that segregation and the introduction of new work routine compartmentalized social classes and the basic activities of work, leisure, and home life to such a degree that 
man the social actor was obliged to play out his encounters in an even greater number of discrete situational settings (35).

Amongst other concerns, such fragmented societies gave rise to anxieties that the practices and sites of established religion were failing to meet the needs of every individual with newfound time for leisure; indeed, such anxieties seem to have prompted the 'anomalous practice of conducting public worship in a theatre' with which this essay began. For while Nottingham was not yet a city in the period we are examining, Bailey's words on societal changes during the nineteenth century may be usefully applied to the town, which witnessed rapid expansion during Victoria's reign, with a population increase from 53,091 in 1841 to 239,745 in 1901 (Church 232; 236). The lack of land for building within the town boundaries prior to the enclosure of common land on the town's periphery in the 1840s, together with the reliance of Nottingham's key industries - lace and hosiery - on small units of production, meant that the 'discrete situational settings' identified by Bailey were clearly marked, making church and chapel a potentially important site for instilling a sense of society and community; the challenge was to attract individuals to join and remain with any given community.

In such circumstances, competition between different denominations for congregations was perhaps inevitable on both a national and local scale: David Cornick highlights the advantages of the "dissenting "denominations" [that] were able to respond to the changes wrought by industrialization more rapidly and flexibly than the Church of England'.

That was because of two inherent advantages - they were financially and legally free, and they possessed a theology of lay ministry (expressed in many forms, from the strictly organized to the chaotically laissez-faire) which enabled them to liberate plant and personnel with ease. (363) 
Such advantages were apparent at the local level, as our analysis of the Nottingham returns in the 1851 religious census demonstrates. On 30 March 1851, for the first and only time, the government carried out a survey of the whole of England and Wales in order to establish how many places of worship were open, how many sittings were provided by each place, and how many of those sittings were occupied at morning, afternoon, and evening services: the results reveal complex variations of religious practice across nation and regions. In Nottingham, the census recorded 38 places of worship, nine of which were controlled by the Church of England including some new satellite churches set up in the outskirts of existing parishes. The rest, with the exception of one Jewish synagogue and the Catholic Church of St Barnabas, were associated with nonconformist and dissenting religious groups, and on the Sunday of the census, total attendance at those venues was significantly higher than for the established Churches: 10,394 for evening service, compared with 4,524 for the nine Church of England sites (comparative figures for morning service, including Sunday scholars, were 9,839 and

\section{6,237 respectively).}

Although these details provide some idea of religious provision within the town, the data was not without controversy: the established Anglican church 'argued that instead of estimating attendances [... the] enumerators should have asked people to give their religious affiliation' (Watts vii), suggesting that the Church of England acknowledged that attendance - or non-attendance - at the many, available 'discrete situational settings' might be prompted by factors other than faith. Thus, while the census data records the physical manifestation of religion in Nottingham at the middle of the nineteenth century, the motivation of attendees is much less certain. The equivocation and defensiveness in such comments, recorded in the census alongside the raw data, provides evidence of the precise form of competition between the Anglican church and 
nonconformist denominations that resulted in an greater choice for the individual within the town.

One response of denominations to such a competitive field was the construction of more places of worship throughout Nottingham. Nonconformist groups certainly monopolised parts of the expanding town after enclosure was undertaken in the 1840s, and, in the thirty years after the 1851 census, the Methodists alone built more than twenty new chapels and missions. The Church of England also erected new buildings, with the large central town parishes recorded in the 1851 census - St. Mary's, St. Peter's and St. Nicholas' - subdividing, throughout the latter part of the nineteenth century, into smaller parishes, each with a church building. For example, by 1871, St. Mary's had been subdivided seven times. George Harwood, a preacher and writer closely connected to the Methodist movement in Nottingham, noted the steadily increasing number of religious venues in his diary of 1863 :

Nottingham has, during the last few years, increased very fast both in houses and inhabitants, and the religious bodies seem to be trying to outstrip each other in providing for the additional population. The Church of England has added several new churches, and is adding more. The Unitarians are building a Chapel in Pease Hill Road, Mr. Little has recently opened the Methodist Independent Church in Great Freeman Street. The New Methodists have purchased a piece of ground on Woodborough Road for the purpose of building a chapel thereon. A piece of ground has been secured for the same object in Great Alfred Street by the United Free Church. The Wesleyans of the North Circuit have built a small chapel in Hartwell Street, and we of the South Circuit are about to erect a good chapel in the Meadows (5 December 1863). 
The wide choice of locations that resulted from all these developments were aimed at a variety of social and economic groups, an attempt to provide new sites of worship for congregations, many at a remove from secular events in the town centre. Yet the result of this increase in religious venues was, of course, increased competition for potential attendees; a returning congregation was required to pay for the construction and consequent upkeep of these buildings.

There were also other, competing claims on leisure time, some of which claimed their own moral qualities: at the opening of the New Theatre Royal in Nottingham in September 1865 the Theatre's Manager, Mr Walter Montgomery, claimed that

With a well-conducted theatre, and with a company of ladies and gentlemen, what is to prevent the drama from fulfilling its great mission, viz., a teacher of the highest morality, nay, even the gentle hand-maiden of religion. [...] there is nothing inconsistent in the following of our profession and the "wearing the light yoke of that Lord of Love who stilled the rolling wave of Galilee' (Nottingham and Midland Counties Daily Express 26 September 1865, 3).

Both church and theatre, then, potentially appealed to the same individuals within Nottingham. With the building of a new theatre in the town, in competition with established and new churches and chapels, secular and religious venues existed within close geographical proximity and in strong tension with each other, inevitably resulting in a competitive form of the 'overlap, complement or conflict' identified by Kong. Our analysis in this chapter of the approaches taken by these venues to the attraction, creation and sustaining of different audiences and congregations within Nottingham, which identifies shared strategies and methods, thus helps to illuminate our understanding of both congregations and audiences and of the wider social networks within the town by highlighting issues of choice and agency which may sit at odds with more conventionally 
understood habits of faith. In this light, religious performance can be seen not just as a demonstration of such faith, but rather as another site within public discourse in which the urban individual could develop and practice his or her subjective identity.

\section{Practising religion, exercising choice}

With this analysis of the religious landscape of Nottingham in mind, it is perhaps unsurprising that developers and administrators of these new religious venues, and of nonconformist sites of worship in particular, were keen to capitalise on the increased mobility and leisure time of subjects in this changing urban environment. In such an environment, relationships between individuals and particular churches can be seen as marked by choice rather than habit: religious historian Horton Davies argues that 'sermon-tasting' - the practice of visiting many different churches to hear notable orators preach - 'was a favourite diversion that also counted as a duty and was thus doubly attractive to the Victorians,' and notes the sustained popularity of the practice within nonconformist denominations particularly throughout the nineteenth century. (vol. 4: 284). 'People from a broad range of social and educational backgrounds attended the services of various notable preachers', suggests Joseph Meisel:

Certainly, some did so out of curiosity or because it was the thing to do; but the fact that these preachers were famous enough to make attendance broadly fashionable indicates the extent to which hearing leading religious orators provided entertainment value (163).

The diary of George Harwood, whose comments on the growth of religious venues in the town we have already seen, provides a specific example of this mobility between religious venues as both preacher and worshipper in Nottingham:

Sunday 30 April, 1865: 
Walked to Carlton, and at 101/2 preached in our Chapel there on Judas, with remarkable freedom. Rode down with Mrs. Taylor to Carlton field and had dinner. Spent the afternoon with Mr. Taylor in conversation about Methodist affairs. [...] After tea, walked through Colwick to Nottingham, and went to Halifax Place Chapel where I heard the Rev. James Daniel, of Wrexham, preach on Martha and Mary.

Harwood's exercise of choice was not exceptional; regular advertisements in Nottingham newspapers, which listed times for special services and sermons alongside the competing demands of theatres and other entertainments in and around the town, suggests an awareness of such practices by different denominations, with each venue working to publicize what was distinctive about the particular form of worship or entertainment they were providing. Such advertisements also reveal the commercial imperatives underpinning a broad programme of services: effective marketing worked to attract individuals who could be encouraged to donate money to ensure the maintenance of church buildings and associated educational institutions.

One example of such advertising can be found in the Nottingham Journal of 17 June 1865, where an announcement provided information on the annual fundraising drive, in Anglican venues, for the Nottingham branch of the Church Missionary Society [Possible Figure 1 inserted here?]. Potential members of the congregations for these sermons are presented with listings for individual venues that seem to encourage choice between churches in the town centre and surrounding villages according to the speakers who would be present (the relative success of these listings is indicated by a report in the Journal of 19 June 1865 of the funds raised at the sermons). ${ }^{2}$ Twelve simultaneous

\footnotetext{
${ }^{2}$ Figures for funds raised across the individual churches are reported as follows: St Mary's
} $£ 20$ 11s. 01/2d.; St Peter's £14 5s.; St James’s £27 9s.; Trinity £27 12s. 101/2d.; Lenton £21 1s. 
morning sermons and thirteen evening sermons happening at the same time as services in nonconformist and dissenting chapels, remind us that individuals could select an event according to shifting preferences and demands. Within the public sphere of performed religion, then, changing conditions within the urban environment opened up the possibility of individual agency in the exercise of choice between available faith-based activities.

Such agency was not limitless - and indeed, the advertising used to evidence its existence here also directs and limits its exercise, as Michael Warner's work on publics and counterpublics makes clear:

The self-organized nature of the public does not mean that it is always spontaneous or organically expressive of individuals' wishes. Although the premise of self-organizing discourse is necessary to the peculiar cultural artifact that we call a public, it is contradicted both by material limits - means of production and distributions, the physical textual objects, social conditions of access - and by internal ones, including the need to presuppose forms of intelligibility already in place, as well as the social closure entailed by any selection of genre, idiolect, style, address, and so on (416).

But while marketing shapes the nature of the choices that can be made, it is still important to note that the very process of selecting a given event, on the part of the social actor - an aspect of the 'self-organizing discourse' - remains a demonstration of individual agency within the public sphere. In place of regular and consistent religious observance at one location as a mark of respectability - most particularly among the middle class residents who would be in a position to purchase newspapers and respond to the advertisements the publicity afforded to exceptional Sunday services implies instead the possible

10d.; New Radford $£ 14$ 8s.; Carrington $£ 10$ 1s; New Radford £15 2s.; Wilford £4 6s. 8d.; annual meeting $£ 404 \mathrm{~s} .10 \mathrm{~d})$. 
operation of a more flexible economy of religious performance practice, based on taste, choice, and social contexts as well as purely religious affiliation, and reflecting the varied simultaneity of events, both religious and secular, available within the still fairly restricted confines of the mid-nineteenth-century town.

\section{Competition and responsiveness: new sites and new performances}

In the light of this more flexible economy of religious practice, different denominations sought to provide a number and variety of activities at different locations that competed with alternative religious and secular events in Nottingham. As with the reports of religious services in the theatre with which this chapter began, religious leaders recognized that established venues might not best serve the needs of potential congregations. Indeed, the religious census returns of 1851 make it clear that the recent consecrations of new venues in Nottingham were prompted by the needs of new areas of population developing in the growing town, with the opening of the Lancasterian School Room as a place of worship on 26 December 1846 said to be 'owing to the remoteness of the population of that Neighbourhood from the parish Church' (quoted in Rogers, 84). Thus, secular sites throughout the town were pressed into use for faith-based activities, most particularly for nonconformist acts of worship, demonstrating the versatile responses to industrial development outlined by Cornick.

An example from the Nottingham Journal of 28 August 1857 illustrates such an approach:

On Tuesday last, about 300 Sunday scholars were provided with a first-rate tea, on the new Cricket Ground, Bath Street, at the nominal charge of $2 \mathrm{~d}$. a head, the expense being defrayed by voluntary subscriptions, promoted by some members of the Primitive Methodist Connexion. The treat originated in a singular movement, 
which has already excited great interest among the religious community. Seven boys assembled on the Cricket Ground, one Sunday evening in May, with the view of establishing a juvenile prayer meeting. The novelty of the thing soon attracted attention, and the meetings have been continued every Sunday evening since; not only children, but their parents and other grown up friends have been induced to attend.

Of interest here is both the site where this event took place - a secular sporting arena - and the role of young residents in the town in initiating attendance. However, of particular significance to an analysis of how denominations attracted their congregations is the manner in which, by developing an initial, spontaneous gathering into a formal event, the Primitive Methodist Connexion enhanced their status and profile within the town. As Harvey, Brace and Bailey observe in writing about Methodist parades and tea treats elsewhere, Moving out of the chapel, parades acted to extend the reach of the institution amongst people who were not normally part of its constituency. It is necessary to understand parades as part of putting religion on display, of articulating belief and of performing faith as a group. Parades and tea treats reaffirmed faith, rewarded attendance and acted as a vehicle for recruitment and retention of members (44). This example also reminds us of the role played by another prominent aspect of religious practice during this period - the Sunday school. This developed into a mid-week activity during the summer months, and therefore frequently took place on the same day as secular events, raising questions about simultaneity and choice making among the individuals who were potentially both congregation and secular audience. On the same Tuesday as the 'first-rate tea' at the Bath Street Cricket Ground, a festival procession through the town followed by a tea party at Trent Bridge Cricket Ground was arranged for scholars attending the Anglican Trinity Sunday and weekday schools - one example, 
perhaps, of a very open competition between opposing religious denominations, with the established religion utilizing the more established and prestigious sporting venue for its 'putting religion on display', in Harvey, Brace and Bailey’s terms. A number of alternative leisure activities were also taking place in the town, further emphasizing the need for awareness that concurrent events were always competing for attendees: while certain events would appeal to very different audiences, some classes of residents might experience both religious and secular events. For example, the 28 August edition of the Journal - which reported on the religious activities at the two cricket grounds - also noted that, during that same week, H. Corri's opera company was appearing at the old Theatre Royal in St. Mary's Gate, and that a picnic party on the banks of the Trent was organised by the landlord of the Carrington Arms. We can add to these entertainments some of the regular attractions in the town, such as an exhibition of history and natural history at the Mechanics' Institute, which had attracted 'a large number of persons, young and old, to examine the collection' (Nottingham Journal 28 August 1857, 5) and, every day of the week including Sundays, when entrance was free, the pleasures of the Nottingham Arboretum, established in 1852.

Here is a varied potential programme of activities within a limited area. Access to some events might be limited by cost or in some cases, by temperance or anti-theatrical concerns, but otherwise all were available to the population of Nottingham - a population who could even, as in the case of the Primitive Methodist Connexion 'treat', initiate these events by their presence in secular spaces in the town, providing further evidence of the 'self-organizing discourse' present within Nottingham, albeit modified by precise social and economic contexts. 
Returning to the winter of 1860 , and the services in secular venues with which this article began, the final service of that year took place in what might at first seem to be an even stranger venue, as the Nottingham Journal of 28 December 1860 reported:

On Sunday evening the Polytechnic Hall, Broad-Street, was the scene of ceremonies very different to those practised generally in that temple of wonders. The gentlemen who have for some time past been engaged in holding religious services at the Theatre it seems have disagreed with the Manager or lessee, and wishing most probably to increase the anomalous nature of the ceremony obtained the use of the Colosseum. The choice of the Colosseum Music Hall - once a Sunday School, but now 'converted, or rather perverted, into a place of low amusement' according to the anonymous critic Asmodeus (78) - was indeed an interesting and anomalous choice for the preachers, one which illustrates the layering of 'simultaneous, fluctuating and conflicting sacred and secular meanings' onto individual locations. Affording a single venue many functions not only echoes Kong's discussion of religious sites, it also places the onus on individual attendees to select from an increasingly sophisticated range of both venues and events.

Such examples establish religious worship in the mid-nineteenth-century industrial town as dynamic and evolving, dependent to some extent upon the choices made by individual residents. Of course, it is important to recognise that not every worshipper moved around the town, choosing different events in which they might participate. Most notably, by the middle of the nineteenth century, a steadily increasing number of children were attending Sunday or weekday schools run by Anglican and nonconformist churches and chapels, forging a consistent relationship between these children, their families, and the relevant site of worship, which - as we have seen above often required new buildings to accommodate them, and the raising of funds to support them. 
Whether a visiting preacher or a regular speaker, the performance given by an individual religious practitioner, the sermon, remained the single, consistent fundraising device employed across denominations. In addition to financial implications, the role of the individual orator, renowned on a national or a local level, in attracting an audience and consequently authorizing a space was paramount, and of particular interest to our analysis of competing religious and secular attractions. Yet, as we have already seen, the role of the preacher in the mid-nineteenth-century was under pressure; the anxiety expressed by Anglican ministers in the 1851 census alludes to factors within and beyond religious practice, as developments in education, literacy, print culture and the entertainment industry competed with religious worship. Davies notes that 'the Victorian preacher was far from being immune from competition' (283); those delivering sermons had to find methods to make individual venues attractive, and to encourage a returning audience to attend faith-based events. In addition to bringing the congregation in, through advertising, it is apparent that preachers, as much as their audience, could move around the town of Nottingham, co-opting secular spaces to attract spectator-worshippers.

One final example demonstrates how this practice appealed to the individual as they selected religious activities. In February 1865, religious and secular entertainments became intimately and obviously related, as the old theatre at St. Mary's Gate was again utilized for a religious service. As the Journal reported:

Yesterday, two religious services were held in the theatre, St. Mary's-gate. The preacher was the Rev. James Caughey, the American revivalist, who had been specially engaged for the purpose, bills distributed during the previous week, inviting the public to 'come and hear the wonder of the world preach Jesus only.' The services, which were held in the afternoon and evening, attracted very large congregations, the stage being thronged by auditors and the other parts of the house 
crowded. After the evening sermon there was a prayer meeting, which was conducted in a most excited manner, a hymn being sung in the gallery and prayer offered on the stage at the same time. Penitent sinners were also handed over the orchestra and footlights from the pit, and conducted to a private service at the back of the stage, the drop scene being lowered to hide the persons engaged in this latter service from the gaze of the rest of the congregation. The promoters of the services were, we believe, the friends worshipping at Park-row chapel, where Mr. Caughey is engaged to preach every evening this week (27 February 1865, 2).

Caughey's presence in the theatre, as with the service in 1860 described at the beginning of this chapter, was an unusual event within the town, prompting significant press coverage. However, where the reports of services in the theatre in 1860 exhibit concern over the melding of theatrical and religious discourses within a single space, here the distinction between stage and auditorium and between religious and secular space seems to have been deliberately diminished during the service, as both the dedicated performance space and order of service were undermined in a frenetic, revivalist entertainment where Caughey's audience could experience a degree of physical and emotional intimacy. The complex use of the space created an effect that could not be achieved in a site of worship, the theatre providing a range of hidden and public spaces and the useful 'drop scene' that allowed Caughey to stage conversion and revelation.

This special service was organized by administrators of a Methodist chapel, who demonstrating the flexibility of response noted by Cornick - chose to hire a secular place of entertainment for the appearance of an internationally renowned preacher. ${ }^{3}$ The

\footnotetext{
${ }^{3}$ Park Row Chapel was built in 1855 to house an offshoot of the Methodist movement, the Wesleyan Congregational Free Church. Its history echoes the story of multivalent usage outlined here: the building was subsequently used by various Methodist groups before being purchased by the Church of England in 1872 and renamed St. Thomas' Church. Caughey
} 
interactive service simultaneously authorized a particular type of worship that could be associated with one chapel in Nottingham, and provided an arena in which residents in a rapidly expanding urban environment, confronted with multiple, competing activities that occurred during their leisure time, were encouraged to become part of a practicing and involved congregation.

By charting such events as examples of the choices that were available to an growing population, it is possible to scrutinize the prominence of competing repertoires and the potential for congregational mobility in Nottingham. Mapping the alternative performances and entertainments - religious and secular - that were available at particular moments has established that, while it may not be possible to chart exact attendance and participation, the analysis of choice within an altering urban landscape can demonstrate how the social actor achieved a measure of agency within institutional frameworks, including that of organized religion.

\section{Works cited}

Asmodeus, Revelations of Life in Nottingham by the English Asmodeus. Nottingham: C.B Truman, ‘Telegraph’ Office, [1860].

Bailey, Peter. Popular Culture and Performance in the Victorian City. Cambridge: Cambridge University Press, 1998.

Booth, Michael. Theatre in the Victorian Age. Cambridge: Cambridge University Press, 1991.

Collinson, Samuel. Diary. Vol 2: 1858-1870. Nottinghamshire Archives. M383.

Cornick, Dabid, 'Post-Enlightenment pastoral care' in A History of Pastoral Care edited by G.R. Evans. London: Cassell, 2000, pp. 362-382. 1844, when among his converts was William Booth, founder of the Salvation Army. 
Church, Roy A. Economic and Social Change in a Midland Town: Victorian Nottingham 1815-1900. London: Cass, 1966.

Davies, Horton. Worship and Theology in England. 4 vols. Princeton: Princeton University Press, 1962.

Harvey, David C., Catherine Brace and Adrian R. Bailey. 'Parading the Cornish subject: Methodist Sunday Schools in west Cornwall, c. 1830-1930'. Journal of Historical Geography 33 (2007): 24-44.

Harwood, George Hodgkinson. The Journal of George Hodgkinson Harwood, 1860-7. Nottinghamshire Archives. M23,788.

Kong, Lily. 'Mapping 'new' geographies of religion: politics and poetics in modernity'. Progress in Human Geography 25.2 (2001): 211-233.

Meisel, Joseph S., Public Speech and the Culture of Public Life in the Age of Gladstone. New York: Columbia University Press, 2001.

Robinson, Jo, Gary Priestnall, Richard Tyler-Jones and Robin Burgess, 'Mapping the Moment: A spatio-temporal interface for studying performance culture, Nottingham, 1857-1867'. International Journal of Humanities and Arts Computing. 5.2 (2011): 103-126.

Rogers, Alan. 'The 1851 Religious Census Returns for the Borough of Nottingham'. Transactions of the Thoroton Society LXXVI (1972): 74-87. Print.

Warner, Michael, 'Publics and Counterpublics (abbreviated version)'. Quarterly Journal of Speech 88.4 (2002): 413-425.

Watts, Michael, ed. Religion in Victorian Nottinghamshire: the Religious Census of 1851. 2 vols. Centre for Local History Record Series 7 Nottingham: University of Nottingham Adult Education Department, 1998. 